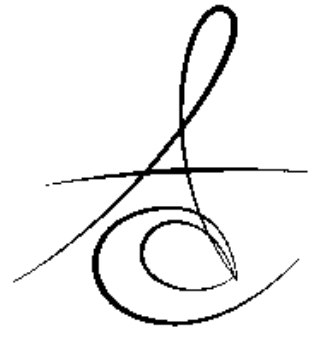

\title{
HAREKETLI FONKSİYONEL APAREY KULLANAN HASTALARDA ORAL C. ALBİCANS KOLONİZASYONUNUN ARAŞTIRILMASI
}

\section{INVESTIGATION OF THE ORAL C. ALBICANS COLONIZATION IN PATIENTS WITH REMOVABLE FUNCTIONAL APPLIANCES}

\author{
Yrd. Doç. Dr. Fundagül BİLGİç* \\ Yrd. Doç. Dr. Özlem AKINCI SÖZER* \\ Yrd. Doç. Dr. Halenur ALTAN ${ }^{* * * *}$
}

\author{
Doç. Dr. Melek İNCİ ${ }^{* *}$ \\ Yrd. Doç. Dr. Yazgı AY*** \\ Yrd. Doç. Dr. Zeki ARSLANOĞLU*****
}

Makale Kodu/Article code: 2548

Makale Gönderilme tarihi: 13.01.2016

Kabul Tarihi: 30.03.2016

\section{öz}

Amaç: $\mathrm{Bu}$ çalışmanın amacı fonksiyonel ortodontik tedavi sırasında kullanılan hareketli apareylerin, hastaların ağız mukozasındaki Candida kolonizasyonunda herhangi bir değişikliğe sebep olup olmadığını tespit etmektir.

Gereç ve Yöntem: Çalışmamız, deney ve kontrol grubu olmak üzere iki gruptan oluşmaktadır. Hareketli fonksiyonel aparey ile tedavi edilecek deney grup 34 hastadan, herhangi bir ortodontik tedavi uygulanmayan kontrol grubu ise 26 hastadan oluşmaktadır. Hareketli aparey kullanan hastalardan, aparey uygulanmadan önce, aparey takıldıktan 1 ay sonra ve 3 ay sonra örnek alındı. Hastalar $10 \mathrm{~mL}$ PBS (phosphate buffered saline) ile $1 \mathrm{dk}$. ağızlarını çalkaladıktan sonra oral yıkama sıvıları toplandı. Bu sıvılar 17000 g'de 10 dk. santrifüj edildi. Örneklerin kloramfenikollü Sabouraud dextrose agara (Merck, Almanya) ekimleri yapıldı ve $37^{\circ} \mathrm{C}$ 'de 48 saat süreyle inkübasyonları sağlandı. Tedavi öncesi, 1 . ay ve 3 . ay sonrasında alınan veriler arasında anlamlı bir farklıık olup olmadığını anlamak için Friedman testi uygulandı.

Bulgular: Deney grubunda, tedavi başlangıcında, çalışmanın 1. ayında ve 3. ayında elde edilen veriler arasında anlamlı bir fark olmadığı tespit edilmiştir. ( $p>0,05)$.

Sonuç: Çalışmamızın sonucunda, hareketli fonksiyonel tedavi sırasında hastaların oral C. Albicans kolonizasyonunda herhangi bir değişiklik olmadığını tespit ettik. Anahtar Kelimeler: Aktivatör; Candida; Ortodonti.

\section{ABSTRACT}

Aim: The aim of this study was to investigated the oral C. Albicans colonization in patients treated with functional removable appliances.

Materials-Methods: This study consisted of two groups, experimental (34 subjects) and control group (26 subjects). The experimental group comprised 34 patients being treated with the removable orthodontic appliances, while the control group who didn't applied orthodontic treatment consisted of 26 patients. Samples were taken from the experimental group patients before treatment, after 1 month and 3 months of treatment. The oral rinses were collected after the patients rinsed their mouths with $10 \mathrm{~mL}$ PBS (phosphate buffered saline) for $1 \mathrm{~min}$. The oral rinses were centrifuged at $17000 \mathrm{~g}$, for $10 \mathrm{~min}$. Samples were inoculated to Sabouraud dextrose agar with chloramphenicol (Merck, Germany) and incubated at $37^{\circ} \mathrm{C}$ for 48 hours.

Friedman test was applied to determine whether there was a significant difference between the data taken before treatment, after 1 month and 3 months of treatment.

Results: In the experimental group, there were no significant differences between pretreatment, 1 month and 3 month values. ( $p>0,05)$.

Conclusion: In our study, there were no significant changes noted in oral $\mathrm{C}$. Albicans colonization of patients during removable functional treatment. Keywords: Activator; Candida; Orthodontics

\footnotetext{
*Mustafa Kemal Üniversitesi, Diş Hekimliği Fakültesi, Ortodonti AD.

**Mustafa Kemal Üniversitesi, Tayfur Ata Sökmen Tıp Fakültesi, Mikrobiyoloji Tıbbi Mikrobiyoloji AD.

***Adnan Menderes Üniversitesi, Diş Hekimliği Fakültesi, Ortodonti AD.

${ }^{* * * *}$ Gaziosmanpaşa Üniversitesi, Diş Hekimliği Fakültesi, Çocuk Diş Hekimliği AD.

${ }^{* * * * *}$ Mustafa Kemal Üniversitesi, Diş Hekimliği Fakültesi, Çocuk Diş Hekimliği AD
} 


\section{GİRIS}

Ortodontik tedavi sırasında ağız içine uygulanan sabit ve hareketli apareyler, hastaların ağız hijyenlerini yeterince sağlayamamasına sebep olabilmektedirler. Bu durumda oral mikrofloranın kompoziyonu ve mikroorganizma miktarı değişebilir. ${ }^{1,2}$ Bu apareyler, biyofilm akümülasyonunu arttırmak, mikrobial kolonizasyonu ve potansiyel mine deminerilizasyonunu yükseltmek, tükürük tampon kapasitesinde değişiklik ve hatta periodontal dokuda zaralı etki oluşturmak gibi ağız içinde birtakım değişiklikler meydana getirirler. ${ }^{3,4}$ Oluşan biyofilm akümülasyonu, deminerilazasyona ve çürük lezyonlarının insidansının artmasına, periodontal hastalıklara ve kronik atrofik candidiazise neden olabilmektedir. ${ }^{3,5-7}$ Biyofilm formasyonu ortodontik aparey uygulandıktan hemen sonra başlamaktadır. ${ }^{8} \mathrm{Bu}$ durumda, ağız hijyeninin yeterli olmadığı durumlarda, bireye uygulanan ortodontik tedavi yarar vermek yerine zarar vererek kötü sonuçların ortaya çıkabilmesine sebep olabilmektedir. ${ }^{9}$

Ortodontik apareyler ağız içine uygulandıktan sonra, spesifik tükürük proteinleri apareyin farklı yüzeyine tutunur ve bu durum bakteri adezyonunda önemli rol oynar. ${ }^{10,11}$ Ortodontik tedavi prosedürlerinin bakteriyemi ile bağlantısı olduğu ve bu hastalardan alınan kan örneklerinde aerobik ve anaerobik bakteri varlığı tespit edilmiştir. ${ }^{12}$

İnsan oral mikro florasında en yaygın olarak bilinen Candida türleri, sağlıklı bireylerin oral kavitesinde ortalama \% 60 oranında kolonize olabilmekte, salyanın her mililitrelik ünitesinde 300-500 kadar koloni kurabilmektedirler. ${ }^{13,14} \mathrm{C}$. Albicans ise en yaygın candida türü olup, oral kavitede bulunan candida türleri arasında en sık rastlanılanıdır. ${ }^{15,16}$ Ortodontik apareyler retantif alanlar yarattığından, sıklıkla Streptococcus mutans (S. Mutans) ve Candida Albicans (C. Albicans) içeren dental plak bakteri kolonizasyonunu arttırmaktadırlar. Bu durum özellikle süresi uzamış hareketli akrilik rezin plak kullanımında önem kazanır. Andresen aktivatörü de akrilik rezinden yapılmış olup, yaklaşık olarak 6 ay boyunca hastaların ağzında kalmakta ve bu akrilik komponentin altında kalın bir biyofilm tabakası oluşabilmektedir. ${ }^{5,8}$

Hareketli tam protezler, sabit ve hareketli ortodontik apareyler, ağız kuruluğu, yüksek şeker oranlı diet ve kötü ağız hijyeni gibi bazı lokal oral faktörler, oral Candida taşıyıcılığının, patojonik forma dönüşüp, bukkal lezyonlarla bağlantılı Candida oluşumuna sebep olabilirler. ${ }^{17}$ Biyofilmdeki bu mikroorganizmalar bazen kan akışına katılır ve bakteriyemiye sebep olurlar. Bu nedenle ortodontik apareylerin sebep olduğu biyofilmin kaldırılması oldukça önem taşımaktadır. ${ }^{18}$

Ortodonti hastalarında Candida kolonizasyonundaki artış, candidiazis gelişeceği anlamına gelmez. Fakat özellikle antibiyotik kullanımı ve apareylerin lokal travma yaratması gibi durumlarda immün sistemin zayıflaması sonucunda infeksiyon riski artabilir. Bağışıklık sistemi baskılanmış çocuklarda candidal infeksiyon riski açısından, ortodontik tedavi sırasında daha tedbirli davranılması gerektiği belirtilmektedir. ${ }^{5}$

Ortodontik tedavi gören hastalarda, uzun tedavi süresinden dolayı oral mikrobiyal değişimi değerlendirmek önemlidir. Bu nedenle ortodontik apareylerin, enfeksiyona yol açabilen oral candidal durumu nasıl etkilediğinin bilinmesi önemlidir. Bu çalışmanın amacı tedavinin ilk üç ayı boyunca, hareketli fonksiyonel ortodontik hastaların ağız mukozasındaki Candida kolonizasyonunda herhangi bir değişiklik olup olmadığını tespit etmektir.

\section{MATERYAL VE METOD}

Mustafa Kemal Üniversitesi Tayfur Ata Sökmen Tıp Fakültesi Klinik Araştırmalar Etik Kurulu'ndan, çalışmamızın uygunluğunu belirten, 26\05\2014\92 sayılı etik kurul raporu alınmıştır. Araştırmamızda, çalışma ve deney grubunu oluşturan hastalar, ortodonti kliniğimize başvuran hastalar arasından rastgele seçilmiştir. Çalışmamız, deney ve kontrol grubu olmak üzere iki gruptan oluşmaktadır. Deney grubu ortodontik tedavi intiyacı olan ve hareketli fonksiyonel bir aparey olan andresen aktivatörü ile tedavi edilecek 34 hastadan, kontrol grubu ise herhangi bir ortodontik tedavi uygulanmayan 26 hastadan oluşmak üzere, çalışmamı toplam 60 bireyden oluşmaktadır. Çalışma grubunu oluşturan 34 hastanın ( 14 kız, 20 erkek) yaş ortalaması 13 yıl 1 ay iken, kontrol grubunu oluşturan 26 hastanın ( $10 \mathrm{kız}, 13$ erkek) yaş ortalaması 13 yıl 8 ay idi. (Tablo 1) Araştırmamıza, sistemik rahatsızlığı bulunmayan, tedavi öncesindeki 6 ay boyunca antibiyotik ya da steroid ilaç kullanmayan, gingivitis yada periodontitis problemi bulunmayan, ağız bakımı iyi olan, mandibular retrüzyon ile karakterize Class II divizyon 1 bireyler dahil edilmiştir. Kontrol grubu cinsiyet, yaş, coğrafik bölge ve sosyal faktörler 
Atatürk Üniv. Diş Hek. Fak. Derg.

J Dent Fac Atatürk Uni

Cilt:26, Sayı:2, Yıl: 2016, Sayfa: 274-278

açısından çalışma grubu ile benzerlik göstermektedir.

Tablo 1. Araştırmaya alınan bireylerin tedavi öncesi yaş dağılımları.

\begin{tabular}{|l|c|c|c|}
\hline & Minimum & Maksimum & Ortalama \\
\hline $\begin{array}{l}\text { Deney } \\
\text { Grubu }\end{array}$ & 11 yıl 2 ay & 15 yıl 3 ay & 13 yll 1 ay \\
\hline $\begin{array}{l}\text { Kontrol } \\
\text { Grubu }\end{array}$ & 12 yll 4 ay & 15 yıl 2 ay & 13 yıl 8 ay \\
\hline
\end{tabular}

Hareketli aparey kullanan hastalardan, aparey uygulanmadan önce, aparey takıldıktan 1 ay sonra ve 3 ay sonra örnek alınmasına karar verildi. Hastalar 10 $\mathrm{mL}$ PBS (phosphate buffered saline) ile $1 \mathrm{dk}$. boyunca ağızlarını çalkaladıktan sonra oral yıkama sıvıları toplandı. Diş hekimliği kliniğine başvuran fakat ortodontik tedaviye intiyacı olmayan kontrol grubundan ise bir kez 10 ml. PBS ile ağızlarını çalkalamaları istendi, daha sonra alınan oral yıkama sıvıları laboratuvara iletildi. Bu sıvilar $17000 \mathrm{~g}$ 'de $10 \mathrm{dk}$. santrifüj edildikten sonra üst kısmı döküldü ve alt kısmı PBS ile tekrar süspanse edildi. Örneklerin Kloramfenikollü Sabouraud Dextrose Agar'a (Merck, Almanya) ekimleri yapıldı ve $37^{\circ} \mathrm{C}$ 'de 48 saat süreyle inkübe edilmeleri sağlandı. Candida türlerinin tanımlanması koloninin morfolojik yapısına, Gram boyamadaki görünüme, germ tüp oluşumuna bakılarak yapıldı. Germ tüp testi sonucunun pozitif bulunması durumunda, C. Albicans olarak tanımlandı.

\section{Ístatistiksel Değerlendirme}

İstatistiksel hesaplamalar için SPSS 16.0 programı kullanılmıştır. Kolmogorov-Smirnov ve Shapiro-Wilk normallik testleri sonucunda deney grubu ile kontrol grubunun normal dağılım göstermediği görülmüştür. Kontrol ve deney gruplarının başlangıç değerleri arasında anlamlı bir fark olup olmadığını sınamak için non-parametrik testlerden Mann-Whitney $U$ testi uygulanmıştır. Deney grubunun tedavi öncesi, 1 . ay ve 3 . ay verileri normal dağılıma uymadığından, üç gruptan alınan veriler arasında anlamlı bir farkılık olup olmadığını tespit etmek için Friedman testi kullanıldı. Tüm analizlerde anlamlılık seviyesi $\mathrm{p}=0.05$ olarak kabul edilmiştir.

\section{BULGULAR}

Yapılan analiz sonucuna göre, kontrol ve deney gruplarının başlangıç değerleri arasında anlamlı bir
BİLGİC, İNCİ, AKINCI SÖZER, AY, ALTAN, ARSLANOĞLU

farklılık saptanmamıştır ( $p>0.05)$. Tablo 2, kayıt alınan zaman aralıklarındaki (tedavi öncesi, 1 . ay ve 3 . ay) C. Albicans bulgularını göstermektedir. Üç farklı zamanda alınan sonuçlar değerlendirildiğinde, C. Albicans prevelansında anlamlı bir fark olmadığı tespit edilmiştir. $(p=0,368)$

Tablo 2. Deney grubunda, farklı zaman periyotlarının C. Albicans prevelansı açısından karşılaştırıması

\begin{tabular}{|c|cccc|}
\hline & \multicolumn{4}{|c|}{$\begin{array}{c}\text { Değerlendirme Aralıkları } \\
\text { Mean } \pm \text { SD }\end{array}$} \\
\hline Değiş̧ken & Başlangıç & 1. Ay & 3. Ay & p \\
\hline $\begin{array}{c}\text { Candida } \\
\text { Albicans }\end{array}$ & $0,11 \pm 0,32$ & $0,11 \pm 0,32$ & $0,20 \pm 0,41$ & 0,368 \\
\hline
\end{tabular}

\section{TARTIŞMA}

Hareketli aparey yapımında kullanılan akriliğin; yapı, boyut ve pürüzsüzlüğüne bağlı olarak, gıda birikimine sebep olduğu ve mikroorganizma proliferasyonunu etkileyebileceği belirtilmektedir. Akrilik yapıya ilaveten, dental hijyende zorlanma, damak derinliği, diş fırçalama tekniği ve sıklığı gibi bazı faktörler de C. Albicans proliferasyonunu etkileyebilmektedir. ${ }^{8}$ Biz de çalışmamızda fonksiyonel ortodontik tedavinin ilk 3 ayı boyunca, hareketli aparey kullanımına bağlı olarak ağızdaki candida kolonizasyonunda herhangi bir değişiklik olup olmadığını tespit etmeyi hedefledik.

Oral mayaların değerlendirilmesinde, oral çalkalama metodunun en hassas metod olduğu belirtilmektedir. ${ }^{15,19}$ Çalışmamızda C. Albicans kolonizasyonunu tespit etmek için, hastalardan PBS (phosphate buffered saline) ile ağızlarını çalkalamalarını istedik.

Araştırmamızda fonksiyonel tedavi öncesi ile tedavinin 1 . ve 3. ay verilerini karşılaştırdığımızda, C. Albicans prevelansında anlamlı bir fark saptamadık. Hibino ve ark. ${ }^{5}$, çalışmalarında hareketli aparey, Candida ve düşük tükürük ph seviyesi arasında direkt bir ilişki olduğunu belirtirlerken, sağlıklı bireylerde ortodontik apareylerden kaynaklı Candida infeksiyonu gelişmediğini tespit etmişlerdir. Arendorf ve Addy ${ }^{20}$, akrilikten yapılmış hareketli apareylerin tükürükteki $\mathrm{pH}$ seviyesinde anlamlı bir düşüşe sebep olduğunu fakat aparey çıkartıldıktan sonra $\mathrm{pH}$ seviyesinin nerdeyse tedavi öncesi değerine gerilediğini belirtmişlerdir. Addy ve ark. ${ }^{21}$, aparey kullanmayan sağlıklı bireyler ile hareketli ve sabit aparey kullanan bireyler arasında candida

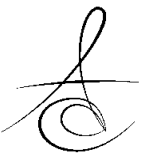


prevelansı arasında anlamlı bir fark bulunmadığını belirtmişlerdir. Çalışmamızın sonucu, araştırmacıların buldukları sonuçlar ile uyum göstermektedir.

Yapılan çalışmalarda, hareketli ve sabit ortodontik apareylerin ağızdaki plak miktarını arttırdığını, fakat kötü ağız hijyeninin candida taşıyıcılığı üzerine direkt etkisi olduğuna dair bir çalışma olmadığı belirtilmektedir. Bununla birlikte apareylerin plak akümülasyonunda artışa sebep olmadığı halde candida densitesinde artış meydana geldiğini belirten çalışmalar da vardır. Bu ilişkiyi açıklamak için gelecekte pekçok çalışmaya ihtiyaç duyulmaktadır. Oral hijyen, candida prevelansı ile bağlantılı önemli faktörlerden biri olsa da, hijyen ve candida prevelansı arasında net bir ilişki olduğunu belirten bir çalışma henüz bulunmamaktadır. $\mathrm{Bu}$ nedenle, ortodontik tedavi gören bireylerin ağızlarındaki Candida varlığının nedenleri, tam olarak bilinmemektedir. $^{5}$

Fakat Bazi araştırmacılara göre sabit ve hareketli ortodontik apareyler, Candida için uygun ortam sağlayan mikrobiyal çevrenin değişmesine sebep olup, hastaların ağız hijyenlerinin sağlanmasını engelleyip ve tükürüğün koruma fonksiyonunu değiştirerek ağızdaki candida prevelansının artmasına sebep olabilmektedirler. Yapılan bir çalışmada, akrilik rezinden yapılmış olan Haas apareyi kullanan bireylerde, Hyrax apareyi kullanan bireylere göre, S. Mutans ve C.albicans sayısının anlamlı şekilde yüksek olduğu tespit edilmiştir. Özellikle fonksiyonel apareylerin, ağızda en az 6-12 ay boyunca kaldıkları için mikrobiyolojik çevreyi etkileyebildiği ve Candida prevelansı ile densitesinde değişikliğe sebep olabildiği de belirtilmektedir. ${ }^{5}$ Aynı zamanda hareketli aparey kullananlara göre sabit ortodontik tedavi gören bireylerin tükürüğünde daha yüksek seviyede Candida olduğu, fakat her iki grupta da apareylerin ağızda kalma süresi uzadıkça Candida kolonizasyonu oranının azaldığı tespit edilmiştir. ${ }^{22}$

Hareketli ortodontik tedavi gören hastalarda yapılan ilk uzun dönemli çalışmada, Candida taşıyıcılığı tedaviden önce 39\% oranındayken, tedaviden 9 ay sonra oranın $79 \%$ 'a çıktığı, tedaviden sonra ise $14 \%$ 'e gerilediği belirtilmiştir. ${ }^{20}$ Arendorf ve Addy ${ }^{20}$, akrilikten yapılmış hareketli apareylerin tükürükteki $\mathrm{pH}$ seviyesinde anlamlı bir düşüşe sebep olduğunu fakat aparey çıkartıldıktan sonra pH seviyesinin nerdeyse tedavi öncesi değerine gerilediğini belirtmişlerdir.

Candida taşıyıcılığı ile hasta direnci arasında ilişki olduğunu belirten çalışmalar da bulunmaktadır.
Mekanik bariyer görevi gören oral mukozal hücreler ve metabolizma, ağız direncinin enfeksiyona karşı direncinin artmasında önemli rol oynadığından, böyle bir durumda Candida, oral epitelde hasar oluşturacak şekilde kolayca yapışabilir. ${ }^{23}$ Araştırmamıza dahil ettiğimiz hastalar sağlıklı bireyler olup, tedavi sırasında C. Albicans prevelansında artış tespit edilmemiştir.

\section{SONUÇ}

Hareketli fonksiyonel tedavi amacı ile Andresen aktivatörü uyguladığımız hastaların oral sıvılarında, tedavinin ilk üç ayı süresince, Candida Albicans kolonizasyonunda herhangi bir artış tespit edilmemiştir.

\section{KAYNAKLAR}

1. Anhoury P, Nathanson D, Hughes CV, Socransky S, Feres M, Chou LL. Microbial profile on metallic and ceramic bracket materials. Angle Orthod 2002;72:338-43.

2. Atack NE, Sandy JR, Addy M. Periodontal and microbiological changes associated with the placement of orthodontic appliances. A review. ] Periodontol 1996;67:78-85.

3. Percy MS. Oral health of adolescents--it's more than dental caries. MCN Am J Matern Child Nurs 2008;33:26-31.

4. Condo R, Casaglia A, Condo SG, Cerroni L. Plaque retention on elastomeric ligatures. $A n$ in vivo study. Oral Implantol (Rome) 2012;5:92-9.

5. Hibino K, Wong RW, Hagg U, Samaranayake LP. The effects of orthodontic appliances on Candida in the human mouth. Int J Paediatr Dent 2009; 19:301-8.

6. Maserejian NN, Trachtenberg F, Hayes C, Tavares $M$. Oral health disparities in children of immigrants: dental caries experience at enrollment and during follow-up in the New England Children's Amalgam Trial. J Public Health Dent 2008;68:14-21.

7. Oliveira LB, Sheiham A, Bonecker M. Exploring the association of dental caries with social factors and nutritional status in Brazilian preschool children. Eur J Oral Sci 2008;116:37-43.

8. Pithon MM SR, Alviano WS, Ruellas ACO, Araújo MRS. Quantitative assessment of S. mutans and C. albicans in patients with Haas and Hyrax expanders. Dental Press J Orthod 2012;17:21.e16. 
9. Bani M, Bani AA. Oral Health Awareness and Rehabilition Oral Health of Orthodontics Patients. Atatürk Üniv Diş Hek Fak Derg 2014;24:442-51.

10. Ahn SJ, Lim BS, Lee YK, Nahm DS. Quantitative determination of adhesion patterns of cariogenic streptococci to various orthodontic adhesives. Angle Orthod 2006;76:869-75.

11. Steinberg $D$, Eyal $S$. Initial biofilm formation of Streptococcus sobrinus on various orthodontics appliances. J Oral Rehabil 2004;31:1041-5.

12. Lucas VS, Omar J, Vieira A, Roberts GJ. The relationship between odontogenic bacteraemia and orthodontic treatment procedures. Eur J Orthod 2002;24:293-301.

13. Fotos PG, Vincent SD, Hellstein JW. Oral candidosis. Clinical, historical, and therapeutic features of 100 cases. Oral Surg Oral Med Oral Pathol 1992;74:41-9.

14. Muzyka BC. Oral fungal infections. Dent Clin North Am 2005;49:49-65, viii.

15. Hagg U, Kaveewatcharanont $P$, Samaranayake $Y H$, Samaranayake LP. The effect of fixed orthodontic appliances on the oral carriage of Candida species and Enterobacteriaceae. Eur J Orthod 2004;26:623-9.

16. Lyon JP, da Costa SC, Totti VM, Munhoz MF, de Resende MA. Predisposing conditions for Candida spp. carriage in the oral cavity of denture wearers and individuals with natural teeth. Can J Microbiol 2006;52:462-7.

17. Vazquez JA, Sobel JD. Mucosal candidiasis. Infect Dis Clin North Am 2009;16:793-820.

18. Mukumoto $M$, Ohshima $T$, Ozaki $M$, Konishi $H$, Maeda N, Nakamura Y. Effect of microbubbled water on the removal of a biofilm attached to orthodontic appliances--an in vitro study. Dent Mater J 2012;31:821-7.

19. Samaranayake LP, MacFarlane TW, Lamey PJ, Ferguson MM. A comparison of oral rinse and imprint sampling techniques for the detection of yeast, coliform and Staphylococcus aureus carriage in the oral cavity. J Oral Pathol 1986;15:386-8.

20. Arendorf TM, Addy M. Candidal carriage and plaque distribution before, during and after removable orthodontic appliance therapy. J Clin Periodontol 1985;12:360-8.

21. Addy M, Shaw WC, Hansford P, Hopkins M. The effect of orthodontic appliances on the distribution of Candida and plaque in adolescents. $\mathrm{Br}$ J Orthod 1982;9:158-63.

22. Khanpayeh E, Jafari AA, Tabatabaei Z. Comparison of salivary Candida profile in patients with fixed and removable orthodontic appliances therapy. Iran J Microbiol 2014;6:263-8.

23. Odds FC. Candida and Candidosis: a Review and Bibliography. London; Balliere Tindall: 1988.

\section{Yazışma Adresi:}

Yrd. Doç. Dr. Fundagül BİLGİÇ

Mustafa Kemal Üniversitesi, Diş Hekimliği

Fakültesi,

Ortodonti Anabilim Dalı, 31100, Hatay, TURKEY.

Tel: +9003262291000

Fax: +90 03262455654

e-mail: fundagulbilgic@hotmail. 